\title{
A mortality prediction rule for non-elderly patients with community-acquired pneumonia
}

\author{
Masato Tashiro ${ }^{1,4^{*}}$, Kiyohide Fushimi ${ }^{6}$, Takahiro Takazono ${ }^{1}$, Shintaro Kurihara ${ }^{4}$, Taiga Miyazaki ${ }^{1}$, Misuzu Tsukamoto ${ }^{4}$, \\ Katsunori Yanagihara ${ }^{5}$, Hiroshi Mukae ${ }^{2}$,Takayoshi Tashiro ${ }^{3}$, Shigeru Kohno ${ }^{2}$ and Koichi Izumikawa $a^{1,4}$
}

\begin{abstract}
Background: No mortality prediction rule is suited for non-elderly patients with community-acquired pneumonia. Therefore, we tried to create a mortality prediction rule that is simple and suitable for non-elderly patients with community-acquired pneumonia.

Methods: Because of low mortality at young age, we used information from an administrative database that included A-DROP data. We analysed the rate and risk factors for in-hospital community-acquired pneumonia-associated death among non-elderly patients and created a mortality prediction rule based on those risk factors.

Results: We examined 49,370 hospitalisations for patients aged 18-64 years with community-acquired pneumonia. The 30-day fatality rate was $1.5 \%$. Using regression analysis, five risk factors were selected: patient requires help for feeding, the existence of malignancy, confusion, low blood pressure, and age 40-64 years. Each risk factor of our proposed mortality risk scoring system received one point. A total point score for each patient was obtained by summing the points. The negative likelihood ratio for the score 0 group was 0.01 , and the positive likelihood ratio for the score $\geq 4$ group was 19.9. The area under the curve of the risk score for non-elderly $(0.86,95 \%$ confidence interval: 0.84-0.87) was higher than that of the A-DROP score $(0.72,95 \%$ confidence interval: $0.70-0.74)(P<0.0001)$.

Conclusions: Our newly proposed mortality risk scoring system may be appropriate for predicting mortality in non-elderly patients with community-acquired pneumonia. It showed a possibility of a better prediction value than the A-DROP and is easy to use in various clinical settings.
\end{abstract}

Keywords: Clinical prediction rule, Mortality, Pneumonia, Young adult, Middle aged

\section{Background}

Community-acquired pneumonia (CAP) remains a major cause of death for elderly and non-elderly people [1-4]. Particularly, in younger and middle-aged adults, most of whom are working-age adults, productivity losses due to death caused by CAP are an important problem from an economic and medical expenses standpoint [4]. It is also important to distinguish patients who are at low risk to prevent over-treatment, because there is a tendency to overestimate the risk of death in patients with CAP [5].

\footnotetext{
* Correspondence: mtashiro@nagasaki-u.ac.jp

'Department of Infectious Diseases, Nagasaki University Graduate School of Biomedical Sciences, 1-7-1 Sakamoto, Nagasaki 852-8501, Japan

${ }^{4}$ Nagasaki University Infection Control and Education Centre, Nagasaki University Hospital, Nagasaki, Japan

Full list of author information is available at the end of the article
}

However, few studies have attempted to distinguish lowrisk CAP patients from high risk ones and determine which patients would benefit when treated as outpatients. Because of these reasons, a precise prediction rule for identifying the severity of CAP is required, especially for non-elderly patients.

There are various indexes for estimating the severity of CAP patients [5-13]. Of those, the most common is the pneumonia severity index (PSI) and the CURB-65 score [9]. However, it is unknown whether both can correctly estimate the severity of CAP in non-elderly patients, because in previous studies, most patients have been elderly [14-19]. Therefore, our study aimed to create a mortality prediction rule suitable for nonelderly patients with CAP. Because of low morbidity and 
mortality at young age, we used information from an administrative database that included A-DROP data.

\section{Methods}

\section{Data source and patient selection}

We used a nationwide dataset available through the Japanese Diagnosis Procedure Combination (DPC) system [20]. This dataset was collected by our survey of DPC hospitals, which voluntarily participated with nondisclosure agreement. Public access to the DPC database was not permitted because it was private database of our study group. The DPC database includes claims and abstract discharge data for all inpatients discharged from $>1,000$ participating hospitals in Japan. We anonymised the data used upon extraction from the DPC database and analysed it within the protected environment of the Nagasaki University Hospital. Informed consent was not required for this study, and the institutional review board of the Nagasaki University Hospital (Nagasaki, Japan) approved the study design (Institutional Review Board No. 15022334).

The present study used data collected from January 2010 to December 2012. Patients' ages were 18-64 years [2]. CAP was defined as the final diagnosis at hospital discharge by the International Classification of Diseases, tenth revision codes (ICD-10): J10-J18 (pneumonia) and J69 (aspiration pneumonia) [2]. We excluded patients who had any missing data from the statistical analyses.

\section{Data extraction}

The following characteristics for each patient were extracted: age; sex; height; weight; final diagnosis; comorbidities on admission with ICD-10 codes; smoking status; Barthel index at admission, including the results of each item; pneumonia severity; length of stay; and death occurring within 30 days of hospital admission. In this study, there were no data after patients' discharge. Comorbidities were evaluated using the Charlson index and the presence of each item [21]. The Charlson index includes seventeen conditions with major impact on survival described as Table 1. For each condition, between one and six points are awarded and summed up for the summary score. Higher score indicate severe comorbidities [22]. The Barthel index is a 10-item measure of activities, such as feeding, moving from a wheelchair to bed and back, personal grooming (washing and shaving face, and combing hair), transferring to and from a toilet, bathing (patient can use a bath tub, a shower, or take a complete sponge bath), walking on a level surface, ascending and descending stairs, dressing, and controlling bowels and bladder [23, 24]. Those were scored according to assistance required by the patient (Additional file 1: Table S1). The total score was from $0-100$ with lower scores representing greater nursing dependency. The pneumonia severity was evaluated using the A-DROP system, which is the modified CURB-65 scoring system proposed by The Japanese Respiratory Society. It assesses Age, Dehydration (existence of a clinical sign of dehydration or blood urea nitrogen level $\geq 210 \mathrm{mg} / \mathrm{L}$ ), Respiratory failure $\left(\mathrm{SpO}_{2} \leq 90 \%\right.$ or $\left.\mathrm{PaO}_{2} \leq 60 \mathrm{mmHg}\right)$, Orientation disturbance (confusion), and a low blood Pressure (systolic blood pressure $\leq 90 \mathrm{mmHg}$ ) [25]. The scoring system stratifies patients into four severity classes (mild $=0$; moderate $=1-2$; severe $=3$; and extremely severe $=4-5$ ), and it has an equal ability for predicting the mortality of CAP compared to the CURB-65 scoring system [6]. In this study, the score for age was 0 points in all patients because all were $<65$ years.

In addition to patients' characteristics, we extracted other factors that may be associated with mortality such as health care region organisational factors, which included the hospital volume, distance from patients' home to the hospital, weekend or holiday admission, and intensive care unit admission [26-29].

\section{Statistical analyses}

We used standard deviations in our analyses. To examine differences in characteristics among groups, Fisher's exact test or Pearson's chi-square test was used to analyse discrete variables, and the Wilcoxon rank sum test was used for continuous variables. The health care region organisational factors were examined for association with CAP mortality by using univariable and multivariable logistic regression analyses. Odds ratios (ORs) and their $95 \%$ confidence intervals (CIs) were calculated. Statistical analyses were performed using JMP 11.2 software (SAS Institute, Cary, NC, USA). All tests were two-tailed, and a $P$-value $<0.05$ was considered statistically significant.

To determine the order of importance of factors predicting 30-day case fatality, we conducted a forward stepwise selection of the factors. The sources of selected factors were the demographics, comorbidities, Barthel index items, parameters of the A-DROP (confusion, dehydration, respiratory failure, and low blood pressure), and health care region organisation. Scores of the Charlson comorbidity and Barthel indices were excluded; alternatively, a particular item of each index was used because calculation of those indexes is difficult in busy clinical settings. Based on the stepwise selection of factors and from a standpoint of ease of use, we selected five items for predicting 30-day mortality. Each risk factor of our proposed mortality risk scoring system received one point. A total point score for each patient was obtained by summing the points. The validity of the new prediction rule compared to the A-DROP system for CAP mortality was evaluated using the receiver operating characteristics (ROC) curve, Kaplan-Meier survival 
Table 1 Baseline characteristics and mortality of the study cohort

\begin{tabular}{|c|c|c|c|}
\hline \multirow[t]{2}{*}{ Characteristic } & No. of cases (\%) & No. (\%) of cases alive at 30 days & $\begin{array}{l}\text { No. (\%) of cases that } \\
\text { died within } 30 \text { days }\end{array}$ \\
\hline & $(n=49,370)$ & $(n=48,638)$ & $(n=732)$ \\
\hline \multicolumn{4}{|l|}{ Sex } \\
\hline Male & $28,070(56.9)$ & $27,550(56.6)$ & $520(71.0)$ \\
\hline Female & $21,300(43.1)$ & $21,088(43.4)$ & $212(29.0)$ \\
\hline \multicolumn{4}{|l|}{ Age, years } \\
\hline $18-39$ & $14,791(30.0)$ & $14,753(30.3)$ & $38(5.2)$ \\
\hline $40-49$ & $7,167(14.5)$ & $7,106(14.6)$ & $61(8.3)$ \\
\hline $50-64$ & $27,412(55.5)$ & $26,779(55.1)$ & $633(86.5)$ \\
\hline \multicolumn{4}{|l|}{ Body mass index $\left(\mathrm{kg} / \mathrm{m}^{2}\right)$} \\
\hline 15 & $2,485(5.0)$ & 2,360 (4.9) & $125(17.1)$ \\
\hline $16-29$ & $44,419(90.0)$ & $43,834(90.1)$ & $585(79.9)$ \\
\hline$\geq 30$ & $2,466(5.0)$ & $2,444(5.0)$ & $22(3.0)$ \\
\hline \multicolumn{4}{|l|}{ Smoking status } \\
\hline Never smoked & $27,883(56.5)$ & $27,506(56.6)$ & $377(51.5)$ \\
\hline Current/ex-smoker & $21,487(43.5)$ & $21,132(43.4)$ & $355(48.5)$ \\
\hline \multicolumn{4}{|l|}{ Charlson comorbidity index } \\
\hline $0-1$ & $37,642(76.2)$ & $37,269(76.6)$ & $373(51.0)$ \\
\hline $2-4$ & $10,534(21.3)$ & $10,270(21.1)$ & $264(36.1)$ \\
\hline$\geq 5$ & $1,194(2.4)$ & $1,099(2.3)$ & $95(13.0)$ \\
\hline Myocardial infarction & $330(0.7)$ & $324(0.7)$ & $6(0.8)$ \\
\hline Congestive heart failure & $2,667(5.4)$ & $2,572(5.3)$ & $95(13.0)$ \\
\hline Peripheral vascular disease & $264(0.5)$ & $259(0.5)$ & $5(0.7)$ \\
\hline Cerebrovascular diseases & $1,497(3.0)$ & $1,458(3.0)$ & $39(5.3)$ \\
\hline Dementia & $201(0.4)$ & $192(0.4)$ & $9(1.2)$ \\
\hline Chronic pulmonary disease & $8,503(17.2)$ & $8,426(17.3)$ & $77(10.5)$ \\
\hline Rheumatic disease & $1,854(3.8)$ & $1,818(3.7)$ & $36(4.9)$ \\
\hline Peptic ulcer disease & $1,910(3.9)$ & $1,886(3.9)$ & $24(3.3)$ \\
\hline Mild liver disease & $2,464(5.0)$ & $2,435(5.0)$ & $29(4.0)$ \\
\hline Diabetes without chronic complications & $4,741(9.6)$ & $4,647(9.6)$ & $94(12.8)$ \\
\hline Diabetes with chronic complications & $1,587(3.2)$ & $1,547(3.2)$ & $40(5.5)$ \\
\hline Hemiplegia or paraplegia & $154(0.3)$ & $153(0.3)$ & $1(0.1)$ \\
\hline Renal disease & $1,490(3.0)$ & $1,444(3.0)$ & $46(6.3)$ \\
\hline Any malignancy & $4,364(8.8)$ & $4,218(8.7)$ & $146(19.9)$ \\
\hline Moderate or severe liver disease & $61(0.1)$ & $56(0.1)$ & $5(0.7)$ \\
\hline Metastatic solid tumour & $860(1.7)$ & $777(1.6)$ & $83(11.3)$ \\
\hline AIDS/HIV & $81(0.2)$ & $80(0.2)$ & $1(0.1)$ \\
\hline \multicolumn{4}{|l|}{ Barthel index (score) } \\
\hline $81-100$ & $37,035(75.0)$ & $36,848(75.8)$ & $187(25.5)$ \\
\hline $41-80$ & $4,733(9.6)$ & $4,644(9.5)$ & $89(12.2)$ \\
\hline $0-40$ & $7,602(15.4)$ & $7,146(14.7)$ & $456(62.3)$ \\
\hline \multicolumn{4}{|l|}{ Requires help with } \\
\hline Feeding & $8,928(18.1)$ & $8,448(17.4)$ & $480(65.6)$ \\
\hline Moving from the wheelchair to the bed & $12,367(25.0)$ & $11,832(24.3)$ & $535(73.1)$ \\
\hline
\end{tabular}


Table 1 Baseline characteristics and mortality of the study cohort (Continued)

\begin{tabular}{|c|c|c|c|}
\hline Personal grooming & $9,842(19.9)$ & $9,345(19.2)$ & $497(67.9)$ \\
\hline Getting on/off toilet & $10,869(22.0)$ & $10,345(21.3)$ & $524(71.6)$ \\
\hline Bathing & $12,610(25.5)$ & $12,065(24.8)$ & $545(74.5)$ \\
\hline Walking on a level surface & $12,581(25.5)$ & $12,035(24.7)$ & $546(74.6)$ \\
\hline Ascending and descending stairs & $13,433(27.2)$ & $12,872(26.5)$ & $561(76.6)$ \\
\hline Dressing & $12,572(25.5)$ & $12,032(24.7)$ & $540(73.8)$ \\
\hline Controlling the bowels & $8,313(16.8)$ & $7,844(16.1)$ & $469(64.1)$ \\
\hline Controlling the bladder & $8,377(17.0)$ & 7,906 (16.3) & $471(64.3)$ \\
\hline
\end{tabular}

Definition of abbreviations: AIDS acquired immune deficiency syndrome, HIV human immunodeficiency virus

curves, and log-rank analyses. Overall, the model prediction was expressed as a c statistic $[2,30]$.

\section{Results}

\section{Baseline characteristics and mortality}

There were 77,819 hospitalised patients with CAP, among which 28,849 patients' data were incomplete. Therefore, we analysed the remaining 49,370 hospitalisations of patients aged 18-64 years with CAP. Table 1 shows the baseline characteristics. The 30 -day case-fatality rate was $1.5 \%$. The percentage of patients who died was higher among men than women $(P<0.0001)$. An older age, high Charlson comorbidity index, low Barthel index, and high severity of pneumonia were associated with a higher mortality $(P<0.0001$, all $)$. Body mass index was also associated with CAP mortality $(P<0.0001)$, particularly in thin patients with a body mass index $<15 \mathrm{~kg} / \mathrm{m}^{2}$ (30-day mortality: $5.0 \%$ ).

As observed in the pneumonia aetiology, aspiration pneumonia had the highest in-hospital mortality (4.5\%), followed by influenza pneumonia (1.8 \%) (Table 2). The lowest mortality was observed for mycoplasmal pneumonia $(0.1 \%)$.

\section{Health care region organisational factors}

Table 3 shows the association between the CAP mortality of non-elderly patients and the health care region organisational factors. As observed in the results of crude ORs, the risk of 30-day mortality was higher in patients who were admitted to a high volume hospital, whose homes

Table 2 Pneumonia characteristics and mortality

\begin{tabular}{|c|c|c|c|}
\hline \multirow[t]{2}{*}{ Characteristic } & No. of cases (\%) & No. (\%) of cases alive at 30 days & $\begin{array}{l}\text { No. }(\%) \text { of cases that died } \\
\text { within } 30 \text { days }\end{array}$ \\
\hline & $(n=49,370)$ & $(n=48,638)$ & $(n=732)$ \\
\hline \multicolumn{4}{|c|}{ Parameters of the A-DROP } \\
\hline Confusion & $927(1.9)$ & $832(1.7)$ & $95(13.0)$ \\
\hline Dehydration & $3,390(6.9)$ & $3,255(6.7)$ & $135(18.4)$ \\
\hline Respiratory failure & $3,940(8.0)$ & $3,779(7.8)$ & $161(22.0)$ \\
\hline Low blood pressure & 6,697 (13.6) & $6,353(13.1)$ & $344(47.0)$ \\
\hline \multicolumn{4}{|l|}{ Pneumonia severity ${ }^{b}$} \\
\hline Mild & $37,094(75.1)$ & $36,845(75.8)$ & $249(34.0)$ \\
\hline Moderate & $11,712(23.7)$ & $11,308(23.2)$ & $404(55.2)$ \\
\hline Severe & $411(0.8)$ & $367(0.8)$ & $44(6.0)$ \\
\hline Extremely severe & $153(0.3)$ & $118(0.2)$ & $35(4.8)$ \\
\hline \multicolumn{4}{|l|}{ Pneumonia aetiology } \\
\hline Pneumococcal & 4,392 (8.9) & $4,361(9.0)$ & $31(4.2)$ \\
\hline Mycoplasmal & $5,010(10.1)$ & $5,004(10.3)$ & $6(0.8)$ \\
\hline Aspiration & $3,586(7.3)$ & $3,425(7.0)$ & $161(22.0)$ \\
\hline Influenza & $167(0.3)$ & $164(0.3)$ & $3(0.4)$ \\
\hline Others $^{c}$ & $36,215(73.4)$ & 35,684 (73.4) & $531(72.5)$ \\
\hline
\end{tabular}

${ }^{a}$ A-DROP assesses confusion, dehydration (the existence of a clinical sign of dehydration or blood urea nitrogen level $\geq 210 \mathrm{mg} / \mathrm{L}$ ), respiratory failure (SpO $2 \leq 90 \%$ or $\mathrm{PaO}_{2} \leq 60 \mathrm{mmHg}$ ), and a low blood pressure (systolic blood pressure $\leq 90 \mathrm{mmHg}$ ). Age was excluded from this table because all patients were $<65$ years ${ }^{\mathrm{b}}$ The pneumonia severity was evaluated using the A-DROP scoring system. Scoring: $0=$ mild, $1-2=$ moderate, $3=$ severe, and $4=$ extremely severe

${ }^{\mathrm{C}}$ This group includes other bacterial or viral and unspecified bacterial pneumonia 
Table 3 Health care region organisational factors

\begin{tabular}{|c|c|c|c|}
\hline \multirow{3}{*}{ Factor } & \multirow[b]{2}{*}{ No. of cases (\%) } & \multicolumn{2}{|c|}{ 30-day mortality } \\
\hline & & Crude OR & Adjusted $\mathrm{OR}^{\mathrm{a}}$ \\
\hline & $(n=49,370))$ & $(95 \% \mathrm{Cl})$ & $(95 \% \mathrm{Cl})$ \\
\hline \multicolumn{4}{|l|}{ Hospital volume (no. of beds) } \\
\hline 200 & $7,373(14.9)$ & Reference & Reference \\
\hline $201-600$ & $31,868(64.5)$ & $1.2(1.0-1.5)$ & $1.0(0.8-1.3)$ \\
\hline$\geq 601$ & $10,129(20.5)$ & $1.7(1.4-2.3)$ & $1.2(0.9-1.5)$ \\
\hline \multicolumn{4}{|c|}{ Distance from the patients' home to the hospital $(\mathrm{km})$} \\
\hline 10 & $14,325(29.0)$ & Reference & Reference \\
\hline $11-30$ & $23,782(48.2)$ & $1.3(1.1-1.5)$ & $0.9(0.8-1.1)$ \\
\hline$\geq 31$ & $11,263(22.8)$ & $1.6(1.3-1.9)$ & $1.0(0.8-1.2)$ \\
\hline Weekend or holiday admission & 10,237 (20.7) & $1.3(1.1-1.5)$ & $1.1(0.9-1.3)$ \\
\hline
\end{tabular}

were far from the hospital, and who were admitted on weekends or holidays. However, the pneumonia severity was also higher in patients with those factors. Therefore, the adjusted ORs showed no significant difference for those factors.

\section{Newly proposed mortality prediction rule}

Stepwise analysis selected the following factors for predicting 30-day mortality: age 40-49 years, age 50-64 years, body mass index $\leq 15 \mathrm{~kg} / \mathrm{m}^{2}$, congestive heart failure, cerebrovascular diseases, any malignancy, metastatic solid tumour, patients requiring help with feeding, patients requiring help ascending and descending stairs, control of the bowels, respiratory failure, confusion, and low blood pressure. Among them, we carefully selected five factors in terms of ease of use and degree of significance for predicting mortality, which included patients requiring help with feeding, the existence of malignancy (any malignancy including metastatic solid tumour), confusion, low blood pressure, and age 40-64 years.

Patients requiring help with feeding were unable to eat, needed assistance cutting food, spreading butter, etc., and required a modified diet. Little is known about the association between CAP mortality and independent feeding in CAP patients. Therefore, we compared characteristics between patients who were independent and those who required help with feeding (Table 4). Patients who required help with feeding were predominately male, were thinner, had a high Charlson comorbidity index, and had a significant lower activity than those who were independent with feeding $(P<0.0001$, all). Interestingly, aspiration pneumonia was a significantly predominant aetiology in patients who required help with feeding $(P<0.0001)$. In addition, these patients' pneumonia was more severe,
Table 4 A comparison of patients' characteristics with and without help feeding

\begin{tabular}{lll}
\hline & Feeding & \\
\cline { 2 - 3 } & $\begin{array}{l}\text { Independent } \\
(n=40,442)\end{array}$ & $\begin{array}{l}\text { Requires help } \\
(n=8,928)\end{array}$ \\
\hline Characteristic & & \\
\hline Personal characteristics & $18,194(45.0)$ & $3,106(34.8)$ \\
Female sex & $47.8 \pm 13.8$ & $50.2 \pm 14.3$ \\
Age, mean years \pm SD & $22.0 \pm 4.5$ & $19.8 \pm 5.4$ \\
Body mass index, mean \pm SD & $0.9 \pm 1.3$ & $1.0 \pm 1.3$ \\
Charlson comorbidity index, mean \pm SD & $96.1 \pm 11.6$ & $15.1 \pm 23.1$ \\
Barthel index, mean \pm SD & & \\
Pneumonia severity & & \\
Mild & $31,983(79.1)$ & $5,111(57.3)$ \\
Moderate & $8,239(20.4)$ & $3,473(38.9)$ \\
Severe & $175(0.4)$ & $236(2.6)$ \\
Extremely severe & $45(0.1)$ & $108(1.2)$ \\
Pneumonia aetiology & & \\
Pneumococcal & $3,789(9.4)$ & $603(6.8)$ \\
Mycoplasmal & $4,770(11.8)$ & $240(2.7)$ \\
Aspiration & $758(1.9)$ & $2,828(31.7)$ \\
Influenza & $137(0.3)$ & $30(0.3)$ \\
Outcome after hospitalisation & & \\
Died within 30 days $^{\mathrm{b}}$ & $252(0.6)$ & $480(5.4)$ \\
Length of stay (days), mean \pm SD & $11.3 \pm 14.0$ & $26.2 \pm 61.1$ \\
\hline De admission & $229(0.6)$ & $439(4.9)$ \\
\hline
\end{tabular}

Definition of abbreviations: $S D$ standard deviation, ICU intensive care unit Data are $n(\%)$ of patients, unless noted otherwise

aThe pneumonia severity was evaluated using the A-DROP scoring system, which assesses confusion, dehydration (the existence of a clinical sign of dehydration or blood urea nitrogen level $\geq 210 \mathrm{mg} / \mathrm{L}$ ), respiratory failure $\left(\mathrm{SpO}_{2} \leq 90 \%\right.$ or $\mathrm{PaO}_{2} \leq 60 \mathrm{mmHg}$ ), and a low blood pressure (systolic blood pressure $\leq 90 \mathrm{mmHg}$ ). Scoring: $0=$ mild, $1-2=$ moderate, $3=$ severe, and $4=$ extremely severe

${ }^{\mathrm{b}}$ The percentages are not equal to $100 \%$ because other bacterial or viral and unspecified bacterial pneumonia are excluded from this table 
and they stayed in the hospital longer and had a high mortality $(P<0.0001$, both $)$.

\section{Validation of the prediction rule}

Table 5 shows regression results for 30-day death among non-elderly patients with CAP using parameters of the A-DROP and the newly proposed five risk factors. Most ORs of the proposed score parameters were higher than that of the A-DROP parameters. Figure 1 shows the ROC curves for the new mortality risk score and ADROP score for non-elderly patients. The area under the curve (AUC) for our method of predicting 30-day mortality was 0.86 (95 \% CI: 0.84-0.87). It was higher than the AUC for the A-DROP score, which was 0.72 (95 \% CI: 0.70-0.74) $(P<0.0001)$.

We also performed a comparison of the Kaplan-Meier survival curves, as classified by the A-DROP score and the new mortality risk score for non-elderly patients (Fig. 2). In both survival curves, there were significant differences between groups $(P<0.0001$, both $)$. Our method identified groups that would not die in the hospital compared to the A-DROP system, as observed in comparison between the score 0 group of our method and the score 0 group of the A-DROP score. Regarding the ability to detect patients who would die in the hospital, the proposed risk score more accurately detected a group with high mortality than the A-DROP score. In addition, the new risk score more clearly divided each

Table 5 Logistic regression for all non-elderly patients who died within 30 days

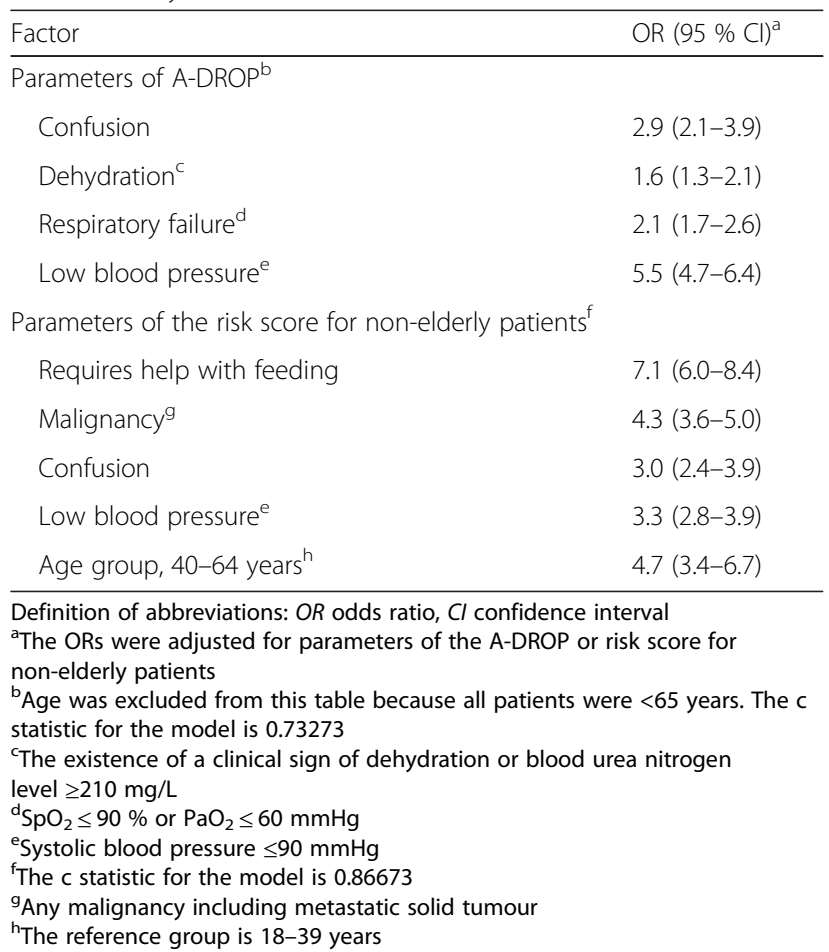

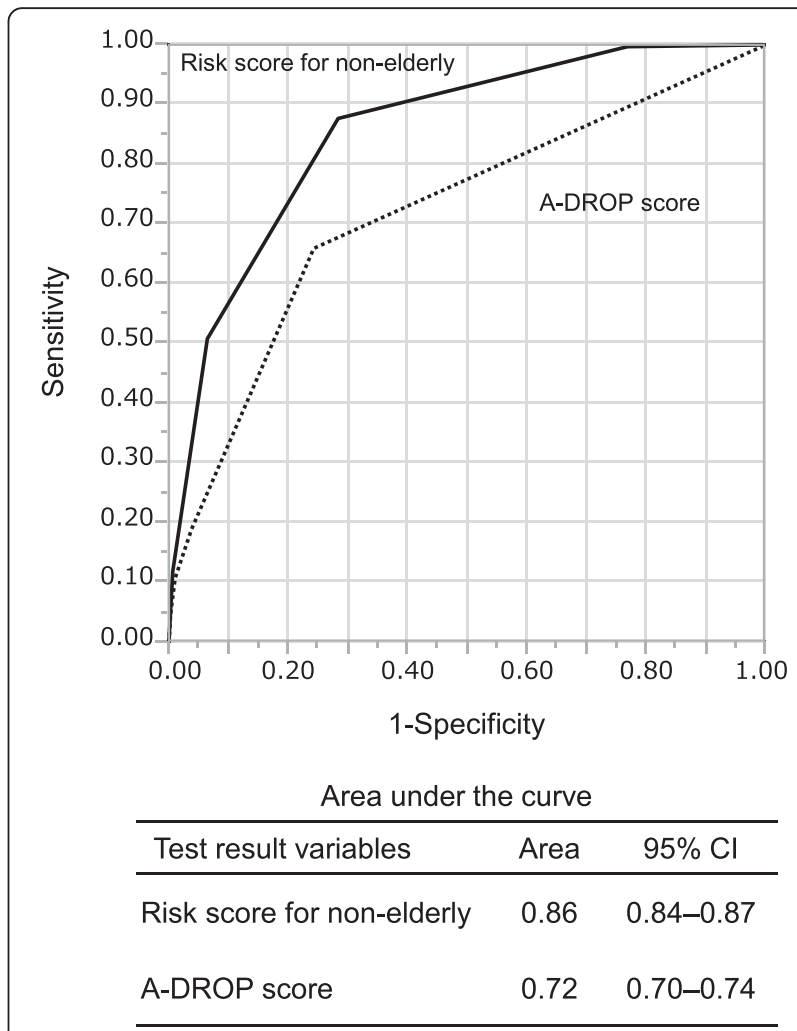

Fig. 1 Receiver operating characteristic curves for predicting 30-day mortality of non-elderly patients with community-acquired pneumonia. The risk score for non-elderly (range, $0-5$ ) is calculated by summing the existence of the following characteristics: patient requires help with feeding; the existence of a malignancy (any malignancy including metastatic solid tumour); confusion; low blood pressure (systolic blood pressure $90 \mathrm{mmHg}$ ), and age 40-64 years. The A-DROP score (range, $0-5$ ) is obtained by summing the existence of the following characteristics: confusion, dehydration (existence of a clinical sign of dehydration or blood urea nitrogen level $\geq 210 \mathrm{mg} / \mathrm{L}$ ), respiratory failure $\left(\mathrm{SpO}_{2} \quad 90 \%\right.$ or $\left.\mathrm{PaO}_{2} \quad 60 \mathrm{mmHg}\right)$, a low blood pressure (systolic blood pressure $90 \mathrm{mmHg}$ ), and age. For A-DROP, scores for age are 0 points in all patients because all are $<65$ years. The area under the curve of the risk score for non-elderly $(0.86,95 \%$ confidence interval [CI]: 0.84-0.87) is higher than that of the A-DROP score $(0.72,95 \% \mathrm{Cl}: 0.70-0.74)(P<0.0001)$

group with different mortalities because margins of mortality between each group were larger in risk scores than in A-DROP scores for non-elderly patients.

Table 6 shows patients' characteristics for each mortality risk score. There was a significant relationship between the risk score and various characteristics, excluding influenza pneumonia (almost $P<0.0001$; influenza pneumonia, $P=0.9158$ ). Particularly, few patients died (only 2 died in 30 days) among 11,297 patients in the lowest risk score (0). The negative likelihood ratio of the score 0 group was 0.01 (95\% CI: $0.00-0.04)$ for 30-day death. The positive likelihood ratio was 19.9 (95\% CI: 15.8-24.9) for the score $\geq 4$ group. 


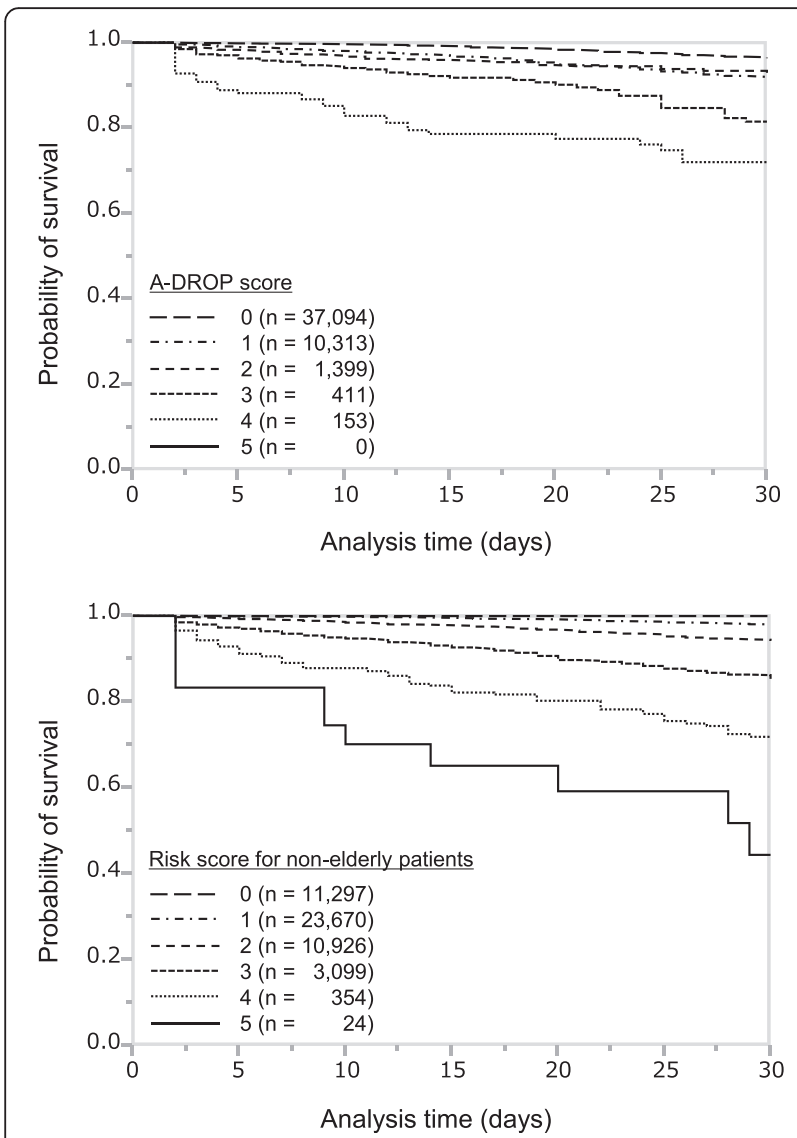

Fig. 2 Kaplan-Meier survival curves classified by the A-DROP score and the risk score for non-elderly. The A-DROP score (range, 0-5) is obtained by summing the existence of the following characteristics: confusion, dehydration (existence of a clinical sign of dehydration or blood urea nitrogen level $\geq 210 \mathrm{mg} / \mathrm{L})$, respiratory failure $\left(\mathrm{SpO}_{2}\right.$ $90 \%$ or $\mathrm{PaO}_{2} \quad 60 \mathrm{mmHg}$ ), a low blood pressure (systolic blood pressure $90 \mathrm{mmHg}$ ), and age. For A-DROP, scores for age are 0 points in all patients because all are $<65$ years. The risk score for non-elderly (range, $0-5$ ) is calculated by summing the existence of the following characteristics: patient requires help with feeding; the existence of malignancy (any malignancy including metastatic solid tumour); confusion; low blood pressure (systolic blood pressure $90 \mathrm{mmHg}$ ), and age 40-64 years. In both survival curves, there are significant differences for each group $(P<0.0001$, all)

\section{Discussion}

Our new mortality risk scoring system had a greater ability for predicting death due to CAP in non-elderly adults. Importantly, this system is easy to use in busy clinical settings, and is based on patients' independence with feeding, the existence of a malignancy, confusion, low blood pressure, and age. Clinicians can evaluate all of these parameters before conducting laboratory tests. The existence of a malignancy can be confirmed by patients' medical history, even though we cannot evaluate its existence in a case on the initial visit. Regarding independence with feeding in patients with CAP, any medical staff can evaluate this quickly. Furthermore, the assigned points consist of only one, and only five factors have to be assessed, which simplify the mortality risk score calculation.

One of our study objectives was to create a new method to prevent unnecessary over-treatment in nonelderly patients with CAP who would survive. It has been reported that only the PSI may be superior at identifying low-risk patients because it achieved a negative likelihood ratio of $<0.1$, whereas the CURB-65 did not [14]. Generally, a negative likelihood ratio of $<0.1$ is regarded as necessary for a predictive or diagnostic test to be considered robust [31]. In our study, the score 0 group among the new risk scores for non-elderly patients achieved a negative likelihood ratio of $<0.1$, but the score $\leq 1$ group did not. We found that patients in the score 0 group would not die in 30 days.

In our study cohort, less than $15 \%$ of patients with severe disease according the risk score proposed were admitted to ICU. In addition, only one patient was admitted in ICU in highest severity of pneumonia (Table 6). The reason of a low ICU rate admission might be due to the fact that the number of ICU beds was smaller in Japan than other countries. Sasabuchi Y et al. reported an ICU-to-hospital bed ratio in their study was relatively small compared with those in Western countries [32]. Therefore some patients with severe disease in Japan were obliged to admit to non-ICU beds.

In a similar study from Canada, Marrie et al. referenced a limitation to their study [2]. They mentioned that their study findings may not be generalisable to other countries. Despite the fact that our study was conducted in Japan, most of the findings were similar to theirs. We confirmed that age, sex, and comorbidity were significantly associated with death in non-elderly patients, and patients with aspiration pneumonia had a high mortality. In addition, larger hospitals had higher case-fatality rates, but this was more likely related to greater comorbidities and the severity of pneumonia. Therefore, these features among non-elderly patients may be similar worldwide. Another limitation to their study was that they did not use the data from a common severity index such as the PSI or CURB-65. We were able to perform our analyses more accurately since we used the A-DROP score.

There are several limitations to our study. First, we could not compare the predictive ability of our new mortality risk scoring system to that of the PSI. To detect lowrisk patients, a non-inferiority comparison between our system and the PSI is needed. Second, a validation cohort such as an outpatient population should confirm this model in the future. Third, there may be several factors associated with mortality that were not considered in this study. For example, our study did not include factors such as the results of laboratory tests, information on drugs used to suppress the immune system, the use of antibacterial agents before admission, a history of hospital 
Table 6 Comparison of characteristics in each group of risk score for non-elderly patients with community-acquired pneumonia

\begin{tabular}{|c|c|c|c|c|c|c|}
\hline \multirow[b]{2}{*}{ Characteristic } & \multicolumn{6}{|c|}{ Risk score for non-elderly patients ${ }^{a}$} \\
\hline & 0 & 1 & 2 & 3 & 4 & 5 \\
\hline No. of patients & $11,297(100.0)$ & $23,670(100.0)$ & $10,926(100.0)$ & $3,099(100.0)$ & $354(100.0)$ & $24(100.0)$ \\
\hline \multicolumn{7}{|l|}{ Personal characteristics } \\
\hline Female sex & $5,928(52.5)$ & $10,464(44.2)$ & $3,929(36.0)$ & $870(28.1)$ & $101(28.5)$ & $8(33.3)$ \\
\hline Age, mean years $\pm S D$ & $30.0 \pm 6.3$ & $51.9 \pm 11.4$ & $56.0 \pm 8.7$ & $57.9 \pm 6.6$ & $59.1 \pm 5.3$ & $59.5 \pm 5.5$ \\
\hline Body mass index $\left(\mathrm{kg} / \mathrm{m}^{2}\right)$, mean $\pm \mathrm{SD}$ & $21.9 \pm 4.7$ & $21.9 \pm 4.8$ & $21.2 \pm 4.9$ & $20.1 \pm 4.6$ & $19.7 \pm 4.3$ & $18.1 \pm 3.9$ \\
\hline Charlson comorbidity index, mean \pm SD & $0.3 \pm 0.6$ & $0.7 \pm 0.9$ & $1.7 \pm 1.6$ & $1.9 \pm 1.8$ & $2.5 \pm 2.0$ & $3.5 \pm 1.6$ \\
\hline Barthel index, mean $\pm S D$ & $97.7 \pm 8.0$ & $89.7 \pm 25.4$ & $63.1 \pm 42.1$ & $31.6 \pm 38.9$ & $16.4 \pm 25.2$ & $7.5 \pm 16.5$ \\
\hline \multicolumn{7}{|l|}{ Pneumonia severity ${ }^{b}$} \\
\hline Mild & $10,485(92.8)$ & $19,996(84.5)$ & $6,294(57.6)$ & $319(10.3)$ & $0(0.0)$ & $0(0.0)$ \\
\hline Moderate & $812(7.2)$ & $3,652(15.4)$ & $4,500(41.2)$ & $2,554(82.4)$ & $194(54.8)$ & $0(0.0)$ \\
\hline Severe & $0(0.0)$ & $22(0.1)$ & $121(1.1)$ & $195(6.3)$ & $67(18.9)$ & $6(25.0)$ \\
\hline Extremely severe & $0(0.0)$ & $0(0.0)$ & $11(0.1)$ & $31(1.0)$ & $93(26.3)$ & $18(75.0)$ \\
\hline \multicolumn{7}{|l|}{ Pneumonia aetiology ${ }^{c}$} \\
\hline Pneumococcal & $897(7.9)$ & 2,345 (9.9) & $878(8.0)$ & $246(7.9)$ & $25(7.1)$ & $1(4.2)$ \\
\hline Mycoplasmal & $2,813(24.9)$ & $1,799(7.6)$ & $362(3.3)$ & $35(1.1)$ & $1(0.3)$ & $0(0.0)$ \\
\hline Influenza & $41(0.4)$ & $79(0.3)$ & $33(0.3)$ & $12(0.4)$ & $2(0.6)$ & $0(0.0)$ \\
\hline Aspiration & $59(0.5)$ & $860(3.6)$ & $1,720(15.7)$ & 855 (27.6) & $86(24.3)$ & $6(25.0)$ \\
\hline \multicolumn{7}{|l|}{ Outcome after hospitalisation } \\
\hline Died within 30 days & $2(0.0)$ & $88(0.4)$ & $270(2.5)$ & $285(9.2)$ & $76(21.5)$ & $11(45.8)$ \\
\hline Length of stay (days), mean \pm SD & $8.0 \pm 5.6$ & $12.1 \pm 17.7$ & $18.8 \pm 29.1$ & $30.2 \pm 70.9$ & $37.3 \pm 155.3$ & $29.2 \pm 36.6$ \\
\hline ICU admission & $30(0.3)$ & $160(0.7)$ & $263(2.4)$ & $181(5.8)$ & $33(9.3)$ & $1(4.2)$ \\
\hline
\end{tabular}

Definition of abbreviations: SD standard deviation

Data are $\mathrm{n}(\%)$ of patients, unless noted otherwise

aEach risk factor (requires help with feeding, malignancy, confusion, low blood pressure, and age 40-64) receives one point. A total point score for each patient is obtained by summing the points

${ }^{\mathrm{b}}$ The pneumonia severity was evaluated using the A-DROP scoring system, which assesses confusion, dehydration (the existence of a clinical sign of dehydration or blood urea nitrogen level $\geq 210 \mathrm{mg} / \mathrm{L}$ ), respiratory failure $\left(\mathrm{SpO}_{2} \leq 90 \%\right.$ or $\mathrm{PaO}_{2} \leq 60 \mathrm{mmHg}$ ), and a low blood pressure (systolic blood pressure $\leq 90 \mathrm{mmHg}$ ).

Scoring: $0=$ mild, $1-2=$ moderate, $3=$ severe, and $4=$ extremely severe

'The percentages are not equal to $100 \%$ because other bacterial or viral and unspecified bacterial pneumonia are excluded from this table

admissions, or socioeconomic status. The income of each individual, which was not included in this study, would never affect the type of treatment because of the universal health insurance coverage in Japan [33]. Fourth, we could not distinguish healthcare-associated pneumonia from CAP, of which the clinical profile is different from that of CAP [34]. Most patients who died may be categorised as healthcare-associated pneumonia because the analysis showed that the existence of a malignancy and reduction of Activities of Daily Living were important risk factors. Fifth, there were several limitations to the administrative databases. Rothberg et al. reported that variation in the use of the principal diagnosis of sepsis or respiratory failure might bias efforts to compare hospital performance regarding pneumonia outcomes [35]. We may have missed severe pneumonia patients with sepsis or respiratory failure because the same phenomenon could have occurred in this study.

\section{Conclusion}

Our newly proposed mortality risk scoring system may be appropriate for predicting the mortality of nonelderly patients with CAP. It showed the possibility of a better prediction value than the A-DROP. Additionally, it was easy to use in various clinical settings. Clinicians should provide these patients with appropriate treatment according to a precise mortality prediction.

\section{Additional file}

Additional file 1: Table S1. Definition of scores for each item of the Barthel index used in this study. (DOCX 49.2kb)

\section{Abbreviations}

CAP: Community-acquired pneumonia; PSI: Pneumonia severity index; DPC: Japanese diagnosis procedure combination; ICD-10: International classification of diseases, tenth revision codes; ORs: Odds ratios; Cis: Confidence intervals; ROC: Receiver operating characteristics. 


\section{Competing interests}

Koichi Izumikawa received honoraria from Pfizer Japan, Inc., Astellas Pharma Inc., and Merck \& Co., Inc. Kiyohide Fushimi received a Grant-in-Aid for Research on Policy Planning and Evaluation from the Ministry of Health, Labour, and Welfare, Japan (H26-Seisaku-Shitei-011). The other authors declare no conflicts of interest.

\section{Authors' contributions}

Study concept, design, analysis, and writing the manuscript: MT. Acquisition the data: KF. Study supervision and critical revision of the manuscript for important intellectual content: all authors. Final approval: all authors.

\section{Acknowledgements}

We would like to thank Editage (www.editage.jp) for English language editing.

\section{Author details}

'Department of Infectious Diseases, Nagasaki University Graduate School of Biomedical Sciences, 1-7-1 Sakamoto, Nagasaki 852-8501, Japan.

${ }^{2}$ Department of Respiratory Diseases, Nagasaki University Graduate School of Biomedical Sciences, Nagasaki, Japan. ${ }^{3}$ Department of Health Sciences, Nagasaki University Graduate School of Biomedical Sciences, Nagasaki, Japan. ${ }^{4}$ Nagasaki University Infection Control and Education Centre, Nagasaki University Hospital, Nagasaki, Japan. ${ }^{5}$ Department of Laboratory Medicine, Nagasaki University Hospital, Nagasaki, Japan. ${ }^{6}$ Department of Health Informatics and Policy, Graduate School of Medicine, Tokyo Medical and Dental University, Tokyo, Japan.

\section{Received: 4 November 2015 Accepted: 23 February 2016} Published online: 08 March 2016

\section{References}

1. Simpson JC, Macfarlane JT, Watson J, Woodhead MA. A national confidential enquiry into community acquired pneumonia deaths in young adults in England and Wales. British Thoracic Society Research Committee and Public Health Laboratory Service. Thorax. 2000;55:1040-5.

2. Marrie TJ, Carriere KC, Jin Y, Johnson DH. Factors associated with death among adults $<55$ years of age hospitalized for community-acquired pneumonia. Clin Infect Dis. 2003;36:413-21.

3. Almirall J, Bolibar I, Vidal J, Sauca G, Coll P, Niklasson B, et al. Epidemiology of community-acquired pneumonia in adults: a population-based study. Eur Respir J. 2000;15:757-63.

4. Bonafede MM, Suaya JA, Wilson KL, Mannino DM, Polsky D. Incidence and cost of CAP in a large working-age population. Am J Manag Care. 2012;18:380-7.

5. Fine MJ, Auble TE, Yealy DM, Hanusa BH, Weissfeld LA, Singer DE, et al. A prediction rule to identify low-risk patients with community-acquired pneumonia. N Engl J Med. 1997;336:243-50.

6. Shindo Y, Sato S, Maruyama E, Ohashi T, Ogawa M, Imaizumi K, et al. Comparison of severity scoring systems A-DROP and CURB-65 for communityacquired pneumonia. Respirology. 2008;13:731-5.

7. Charles PG, Wolfe R, Whitby M, Fine MJ, Fuller AJ, Stirling R, et al. SMART-COP: a tool for predicting the need for intensive respiratory or vasopressor support in community-acquired pneumonia. Clin Infect Dis. 2008;47:375-84.

8. Barlow G, Nathwani D, Davey P. The CURB65 pneumonia severity score outperforms generic sepsis and early warning scores in predicting mortality in community-acquired pneumonia. Thorax. 2007;62:253-9.

9. Lim WS, van der Eerden MM, Laing R, Boersma WG, Karalus N, Town Gl, et al. Defining community acquired pneumonia severity on presentation to hospital: an international derivation and validation study. Thorax. 2003;58:377-82.

10. Espana PP, Capelastegui A, Gorordo I, Esteban C, Oribe M, Ortega M, et al. Development and validation of a clinical prediction rule for severe communityacquired pneumonia. Am J Respir Crit Care Med. 2006;174:1249-56.

11. Mandell LA, Wunderink RG, Anzueto A, Bartlett JG, Campbell GD, Dean NC, et al. Infectious Diseases Society of America/American Thoracic Society consensus guidelines on the management of community-acquired pneumonia in adults. Clin Infect Dis. 2007;44 Suppl 2:S27-72.

12. Musher DM, Thorner AR. Community-acquired pneumonia. N Engl J Med. 2014;371:1619-28.

13. Waterer GW, Rello J, Wunderink RG. Management of community-acquired pneumonia in adults. Am J Respir Crit Care Med. 2011;183:157-64.

14. Chalmers JD, Singanayagam A, Akram AR, Mandal P, Short PM, Choudhury G, et al. Severity assessment tools for predicting mortality in hospitalised patients with community-acquired pneumonia. Systematic review and meta-analysis. Thorax. 2010;65:878-83.

15. Atlas SJ, Benzer TI, Borowsky LH, Chang Y, Burnham DC, Metlay JP, et al. Safely increasing the proportion of patients with community-acquired pneumonia treated as outpatients: an interventional trial. Arch Intern Med. 1998;158:1350-6.

16. Marrie TJ, Lau CY, Wheeler SL, Wong CJ, Vandervoort MK, Feagan BG. A controlled trial of a critical pathway for treatment of community-acquired pneumonia. CAPITAL Study Investigators. Community-acquired pneumonia intervention trial assessing levofloxacin. JAMA. 2000;283:749-55.

17. Carratala J, Fernandez-Sabe N, Ortega L, Castellsague X, Roson B, Dorca J, et al. Outpatient care compared with hospitalization for communityacquired pneumonia: a randomized trial in low-risk patients. Ann Intern Med. 2005;142:165-72.

18. Yealy DM, Auble TE, Stone RA, Lave JR, Meehan TP, Graff LG, et al. Effect of increasing the intensity of implementing pneumonia guidelines: a randomized, controlled trial. Ann Intern Med. 2005;143:881-94.

19. Renaud B, Coma E, Labarere J, Hayon J, Roy PM, Boureaux H, et al. Routine use of the pneumonia severity index for guiding the site-of-treatment decision of patients with pneumonia in the emergency department: a multicenter, prospective, observational, controlled cohort study. Clin Infect Dis. 2007;44:41-9.

20. Tagami T, Matsui $H$, Horiguchi H, Fushimi K, Yasunaga H. Low-dose corticosteroid use and mortality in severe community-acquired pneumonia patients. Eur Respir J. 2015:45:463-72.

21. Sundararajan V, Quan H, Halfon P, Fushimi K, Luthi JC, Burnand B, et al. Cross-national comparative performance of three versions of the ICD-10 Charlson index. Med Care. 2007;45:1210-5.

22. Sundararajan V, Henderson T, Perry C, Muggivan A, Quan H, Ghali WA. New ICD-10 version of the Charlson comorbidity index predicted in-hospital mortality. J Clin Epidemiol. 2004;57:1288-94.

23. Quinn TJ, Langhorne P, Stott DJ. Barthel index for stroke trials: development, properties, and application. Stroke. 2011:42:1146-51.

24. Murcia J, Llorens P, Sanchez-Paya J, Reus S, Boix V, Merino E, et al. Functional status determined by Barthel Index predicts community acquired pneumonia mortality in general population. J Infect. 2010;61:458-64.

25. Miyashita N, Matsushima T, Oka M, Japanese RS. The JRS guidelines for the management of community-acquired pneumonia in adults: an update and new recommendations. Intern Med. 2006;45:419-28.

26. Ross JS, Normand SL, Wang Y, Ko DT, Chen J, Drye EE, et al. Hospital volume and 30-day mortality for three common medical conditions. N Engl J Med. 2010;362:1110-8

27. Joynt KE, Orav EJ, Jha AK. Mortality rates for Medicare beneficiaries admitted to critical access and non-critical access hospitals, 2002-2010. JAMA. 2013:309:1379-87

28. Yu VL, Stout JE. Rapid diagnostic testing for community-acquired pneumonia: can innovative technology for clinical microbiology be exploited? Chest. 2009;136:1618-21.

29. Wilson KC, Schunemann HJ. An appraisal of the evidence underlying performance measures for community-acquired pneumonia. Am J Respir Crit Care Med. 2011;183:1454-62.

30. Kruger S, Ewig S, Giersdorf S, Hartmann O, Suttorp N, Welte T, et al. Cardiovascular and inflammatory biomarkers to predict short- and long-term survival in community-acquired pneumonia: Results from the German Competence Network, CAPNETZ. Am J Respir Crit Care Med. 2010;182:1426-34

31. Deeks JJ, Altman DG. Diagnostic tests 4: likelihood ratios. BMJ. 2004;329:168-9.

32. Sasabuchi $Y$, Yasunaga $H$, Matsui $H$, Lefor AK, Horiguchi H, Fushimi K, et al. The volume-outcome relationship in critically ill patients in relation to the ICU-to-hospital bed ratio. Crit Care Med. 2015;43:1239-45.

33. Kohda M. How does Japan do it? Universal health insurance coverage in Japan. EBRI Issue Brief. 1993;136:35-8.

34. Shindo $Y$, Ito R, Kobayashi $D$, Ando M, Ichikawa M, Shiraki A, et al. Risk factors for drug-resistant pathogens in community-acquired and healthcareassociated pneumonia. Am J Respir Crit Care Med. 2013;188:985-95.

35. Rothberg MB, Pekow PS, Priya A, Lindenauer PK. Variation in diagnostic coding of patients with pneumonia and its association with hospital risk-standardized mortality rates: a cross-sectional analysis. Ann Intern Med. 2014;160:380-8. 